\title{
Ultra-sonografia e ressonância magnética em um hospital de ortopedia: uma preocupação com o processo de aprendizagem e ensino
}

\author{
Márcio Martins Machado', Ana Cláudia Ferreira Rosa', Válney Luiz da Rocha ${ }^{2}$, Edegmar Nunes Costa ${ }^{3}$, \\ Rubens Carneiro dos Santos Júnior ${ }^{4}$
}

A convite do Hospital de Acidentados de Goiânia, em fevereiro de 2002 assumimos (M.M.M. e A.C.F.R.) a Divisão de Radiologia Músculo-Esquelética e de Emergência deste hospital. A idéia era desenvolvermos uma inter-relação mais estreita entre as novas aquisições na área de diagnóstico por imagem - em especial a ultra-sonografia (US) e a ressonância magnética (RM) — e os achados clínico-cirúrgicos.

O hospital, composto por 15 ortopedistas de nossa cidade, muitos dos quais professores do Departamento de Ortopedia da Faculdade de Medicina da Universidade Federal de Goiás (FM-UFG), já possuía histórica produção no sentido da correlação entre os achados da radiologia geral e de tomografia computadorizada (TC) com aqueles da clínica e cirurgia. Conseguiam isto por possuírem um arquivo de todos os casos do hospital, inclusive com os exames de imagem, sempre com a participação concomitante das atividades desenvolvidas no Departamento de Ortopedia da FM-UFG. Ademais, assim como no Departamento supracitado, o Hospital de Acidentados de Goiânia é estruturado em grupos, possuindo o grupo da cirurgia do pé, joelho, quadril adulto e infantil, coluna, cotovelo e ombro, o da cirurgia da mão, bem como o da microcirurgia. Este fato corrobora ainda mais a seriedade de estudos advindos deste grupo.

Quando do convite, tivemos muita honra em aceitá-lo. Isto não somente pelo aspecto do trabalho como radiologistas, mas pela possibilidade de agregarmos os exames de US e de RM neste processo de inter-relação com a clínica e a cirurgia. Evidentemente, os ortopedistas já realizavam este tipo de correlação há vários anos, mas sem contudo contar com a presença diuturna do radiologista.

Com a nossa chegada, introduzimos no Hospital de Acidentados a US músculoesquelética. Já os exames de RM solicitados pelos ortopedistas deste Hospital são realizados por nós no Serviço de Ressonância Magnética do Instituto de

\footnotetext{
1. Responsáveis pela Divisão de Radiologia Músculo-Esquelética e de Emergência do Centro de Diagnóstico do Hospital de Acidentados de Goiânia, Doutores em Radiologia pela Faculdade de Medicina da Universidade de São Paulo (FMUSP), Médicos Radiologistas Cooperados do Departamento de Radiologia da Faculdade de Medicina da Universidade Federal de Goiás (FM-UFG).

2. Professor e Chefe do Departamento de Ortopedia da FM-UFG, Ortopedista do Hospital de Acidentados de Goiânia.

3. Professor e Chefe do Grupo de Pé do Departamento de Ortopedia da FM-UFG, Ortopedista do Hospital de Acidentados de Goiânia.

4. Professor do Departamento de Radiologia da FM-UFG, Chefe do Serviço de Ressonância Magnética do Instituto de Neurologia de Goiânia.

Endereço para correspondência: Dr. Márcio Martins Machado. Rua 1027, no 230, Edifício Fabiana, ap. 304, Setor Pedro Ludovico. Goiânia, GO, 74823-120. E-mail: marciommachado@ibest.com.br
} 
Neurologia de Goiânia, a convite do radiologista Prof. Dr. Rubens Carneiro, diretor do Serviço de Ressonância Magnética deste Instituto.

Entendidas estas colocações, é fácil perceber como se desenvolve de maneira fluida o processo de aprendizagem e ensino. O paciente é atendido pelos médicos do hospital e são submetidos aos mais diversos exames (radiografias, TC, US e RM). A maioria destes exames é realizada por nós (M.M.M. e A.C.F.R.), e aqueles que porventura não são, sempre são reavaliados por nós em conjunto com os ortopedistas.

Após a análise do quadro clínico e dos exames de imagem, em avaliação multidisciplinar, envolvendo a nossa participação com a dos ortopedistas do hospital, realiza-se o processo de tomada da conduta clínica ou cirúrgica.

No caso de decisão cirúrgica, nós (os radiologistas do hospital) ainda temos a felicidade de podermos ir ao centro cirúrgico e verificar os achados intra-operatórios, ampliando sobremaneira a correlação com os resultados dos exames de imagem realizados ou avaliados por nós (em reuniões multidisciplinares, como citado anteriormente). Isto somente é possível pelo fato de um de nós estar sempre presente no hospital.

Com relação ao processo de ensino, temos tido a oportunidade de discutir nossas experiências no Departamento de Ortopedia da FM-UFG, mostrando a complexa inter-relação existente entre a formulação da hipótese diagnóstica clínica, a hipótese diagnóstica formulada pelos exames de imagem, e o diagnóstico definitivo dado nos casos comprovados pela cirurgia.

No nosso entendimento, somente com muita humildade e com esta obsessiva busca pela correlação clínico-cirúrgica e radiológica poderemos caminhar no sentido do aprimoramento do saber, reconhecendo os erros com dignidade e reafirmando os acertos. Agindo dessa forma, poderemos contribuir no campo da ortopedia e da radiologia músculo-esquelética, com a difusão de ensinamentos baseados em correlações científicas com comprovada confirmação etiológica. 